\title{
Coronary Artery Spasm, Hypertension, Hypokalemia and Licorice
}

\section{Ewa Konik ${ }^{1, *}$, Emily Graham Kurtz ${ }^{1}$, Flora Sam² and Douglas Sawyer ${ }^{1}$}

${ }^{1}$ Vanderbilt University, Nashville, TN, USA

${ }^{2}$ Boston University School of Medicine, Boston, MA, USA

\section{Introduction}

Hypertension with hypokalemia, especially in a patient off diuretics, suggests a secondary hypertension due to an increase in mineralocorticoid activity, for example, primary increases in renin, aldosterone, or nonaldosterone mineralocorticoid secretion or an increased mineralocorticoid-like effect.

Mineralocorticoid Receptors (MR) preferentially bind cortisol. A mineralocorticoid effect of cortisol is avoided in some tissues by expression of 11-Beta Hydroxysteroid Dehydrogenase type 2 (11 BHSD2), the enzyme responsible for transformation of cortisol to its 11-keto derivative (cortisone), which has minimal affinity for MR receptors. Only when cortisol is converted to the inactive cortisone can aldosterone bind to the MR. Rare congenital deficiency of 11 BHSD 2 or its inhibition by licorice consumption mimics hyperaldosteronic state [1].

11 BHSD2 is expressed in the distal tubulus in the kidney, but also in the vascular smooth muscle cells and endothelial cells. There is evidence that licorice consumption enhances vasoconstriction action in vascular smooth muscles via inhibition of 11 BHSD2 with subsequent alterations in endothelin- 1 and nitric oxide systems (Figure 1). Inhibition of both, renal and vascular 11 BHSD2 contributes to the development of hypertension with chronic licorice ingestion [2].

Whereas the development of hypertension and hypokalemia as a side effect of chronic licorice consumption is well documented, there are only a few reported cases linking licorice consumption to vasospasm, such as vasospasm-mediated transient visual loss, migraines and Posterior Reversible Encephalopathy Syndrome (PRES) $[3,4]$. Licorice could potentially contribute to development of coronary artery spasm via changes in endothelin and NO systems. Given the rarity of this presentation, additional factors such as history of migraines and caffeine consumption as well as genetic predisposition might play a role.

\section{Case Description}

A 51-year-old woman with hypertension, hypokalemia, dyslipidemia, migraines and a history of two episodes of coronary artery spasm was referred to our facility for cardiologic evaluation.

Nine months prior to the referral, she presented to the ED with substernal chest pain radiating to the left arm. At that time her only medication was rosuvastatin. Her blood pressure was $180 / 93 \mathrm{mmHg}$ and pulse 64 beats per minute. The pain decreased from 10 to 3 out
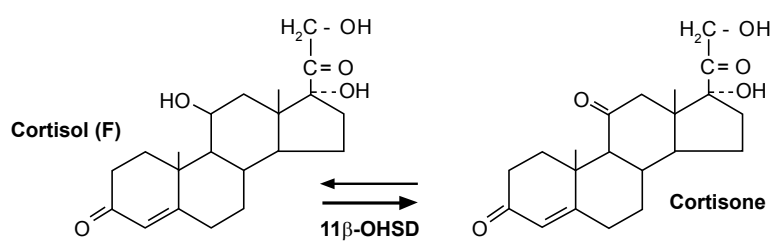

Figure 1: 11 BHSD2 normally inactivates cortisol. Glycyrrhizin, active principle of licorice, inhibits $11 \mathrm{BHSD} 2$, which increases free cortisol locally to act as the mineralocorticoid [1]. of 10 after sublingual nitroglycerine. ECG showed ST-segment elevations in the inferior leads. Initial troponin was 0.05 . Potassium was $3.5 \mathrm{mEq} / \mathrm{L}$. An emergently performed coronary angiogram showed angiographically normal coronary arteries and left ventriculogram revealed minimal apical hypokinesis and normal EF of 55-65\%. Blood pressure measured in the aorta was $162 / 95 \mathrm{mmHg}$ and the patient received labetalol $20 \mathrm{mg}$ IV. Serially measured troponin values showed troponin of 0.49 at about $6 \mathrm{~h}$ and 64.88 at about $24 \mathrm{~h}$ after the initial presentation. The patient was discharged on the aspirin $325 \mathrm{mg}$ once daily, clopidogrel $75 \mathrm{mg}$ once daily, Imdur (isosorbide mononitrate ER) $30 \mathrm{mg}$ once daily, diltiazem ER $180 \mathrm{mg}$ once daily, and rosuvastatin $5 \mathrm{mg}$ once daily.

The dyspnea and chest pain recurred three weeks later. At that time ECG showed $\mathrm{T}$ wave inversions in the inferior and anterolateral leads. A myocardial perfusion stress test showed a small reversible perfusion defect in the apical wall. Repeated coronary catheterization showed angiographically normal coronary arteries. K was $3.3 \mathrm{mEq} / \mathrm{L}$ and KCL $20 \mathrm{mEq}$ once daily was prescribed. After these two episodes, the patient had "twinges across her chest and shortness of breath every once in a while".

Her past medical history was otherwise unremarkable. She had no known drug allergies. Her current medications included aspirin 325 mg once daily, clopidogrel $75 \mathrm{mg}$ once daily, diltiazem ER $180 \mathrm{mg}$ once daily, rosuvastatin $5 \mathrm{mg}$ once daily, and KCL $20 \mathrm{mEq}$ once daily. Her family history was significant for coronary artery disease, with a history of CABG in her father and an abdominal aortic aneurysm rupture in her sister. She quit smoking nine years prior to the presentation. A complete review of the body systems was unremarkable. Her vital signs showed blood pressure $132 / 80 \mathrm{mmHg}$, pulse 76 , respiratory rate 16 , weight 113.3 lbs. The physical exam was unremarkable.

The history of hypertension and hypokalemia prompted an additional review of over-the- counter medication and diet, which revealed licorice consumption. Her average licorice consumption per week was 800-1220 gram. The patient ate on average one bag of Young \& Smylie (black; 283 gram or 368 gram) or one bag of twizzlers (black or cherry; 453 gram) per week and 3-4 boxes of Good and Plenty and snaps $(3-4 \times 170$ gram $=510-680$ gram $)$ per week. All of the above licorice candies except cherry twizzlers contain licorice extract [5] Patient's caffeine intake was approximately 4 cups a day.

She was unaware of the hypertensive licorice properties and believed that licorice as a low fat snack is a healthy food choice. We

*Corresponding author: Ewa Konik, MD, Vanderbilt University, Nashville, TN USA, E-mail: ewa.konik@gmail.com

Received March 05, 2012; Accepted May 05, 2012; Published May 14, 2012

Citation: Konik E, Kurtz EG, Sam F, Sawyer D (2012) Coronary Artery Spasm Hypertension, Hypokalemia and Licorice. J Clin Case Rep 2:143. doi:10.4172/21657920.1000143

Copyright: $\odot 2012$ Konik E, et al. This is an open-access article distributed under the terms of the Creative Commons Attribution License, which permits unrestricted use, distribution, and reproduction in any medium, provided the original author and source are credited. 
recommended discontinuation of licorice consumption and stopping potassium supplement.

2 weeks and 1.5 months after discontinuing licorice and potassium supplement, the potassium was $4.2 \mathrm{mEq} / \mathrm{L}$ and $4.1 \mathrm{mEq} / \mathrm{L}$, respectively. Blood pressure on diltiazem ER $180 \mathrm{mg}$ once daily was $126 / 82 \mathrm{mmHg}$ 1.5 months after licorice discontinuation (as compared to 132/80 $\mathrm{mmHg}$ on our first evaluation). Further self-monitored blood pressure readings over a one week period showed an average blood pressure of $117 / 74 \mathrm{mmHg}$ with pulse of 71 beats per minute. The patient noted one episode of migraine ("woke up with really bed migraine") in her diary, however no recurrence of chest pain.

Further testing performed in our facility included TTE, coronary arteries calcium score, and ultrasonography of the abdominal aorta. TTE showed normal biventricular function, grade I diastolic dysfunction and mild apical hypokinesis. The coronary arteries calcium score was zero and the diameter of abdominal aorta was normal.

We considered to re-challenge the patient with licorice. However given her excellent response to cessation of licorice consumption as well as potential adverse outcome of provoking coronary artery spasm, we decided to forego it.

\section{Discussion}

Impaired vasodilatation, enhanced vasoconstriction, or combination of both can cause vasospasm [6]. Active compounds of licorice, glycyrrhizic and glycyrrhetinic acid, influence endothel and smooth muscle cell function via NO and endothelin systems, which play a major role in vasodilatation and vasoconstriction.

Licorice species are perennial herbs which contain glycyrrhizic acid. Glycyrrhizic acid is 50 times as sweet as sugar. In fact, the name "licorice" means "sweet root" in Greek (glukus "sweet" and rhiza "root"). The sweetness and licorice flavor are well known to consumers of licorice candies. In most sorts of these candies the taste is reinforced by aniseed oil, and the actual content of licorice varies [7]. Licorice has a long history of medicinal use for various conditions and is also used for tobacco flavoring.

In rats with glycyrrhizic acid-induced hypertension there was an increase of endothelin-1 (ET-1) and decrease of eNOS and nitrate concentration in aortic tissue. Hypertension as well as alteration of ET1 , eNOS, and nitrate concentration in aortic tissue were normalized by MR antagonists (spironolactone and eplerenone). Endotheliumdependent relaxation of aortic rings was blunted after licorice treatment and was normalized by aldosterone receptor antagonists. Chronic $\mathrm{ET}_{\mathrm{A}}$ receptor blockade and verapamil normalized blood pressure. Only chronic $\mathrm{ET}_{\mathrm{A}}$ receptor blockade but not verapamil normalized levels of ET-1, eNOS, and nitrate in aortic tissue. ET-1-induced contractions of aortic rings were enhanced after chronic glycyrrhizic acid ingestion and ameliorated by both aldosterone receptor antagonists and $\mathrm{ET}_{\mathrm{A}}$ receptor blockade, but not verapamil [8].

In another study, both spironolactone and darusentan, $\mathrm{ET}_{\mathrm{A}}$ receptor antagonist, completely reversed licorice-induced hypertension in rats. Relaxation of pre-constricted renal artery rings from the licorice-induced hypertensive rats in response to ACh was impaired. Spironolactone treatment completely normalized the response to Ach, whereas darusentan has only improved it. Endothelium independent relaxation to nitroprusside was unaffected by licorice [9]

Sobieszczak et al. showed that inhibition of 11 BHSD2 by glycyrrhetinic acid in healthy human subjects tended to reduce the forearm blood flow response to metacholine and significantly reduced the forearm blood flow response to verapamil. The authors concluded that inhibition of 11 BHSD2 attenuated vascular smooth muscle vasodilatory function [10].

Miettinen et al. [11] recruited 30 human subjects with documented history of licorice-induced hypertension and screened their DNA samples for variants of the genes encoding 11 BHSD2 as well as $\alpha$-, $\beta$-, and $\gamma$-subunits of the Epithelial Sodium Channels $(\mathrm{ENaC})$ previously shown to be associated with hypertension. No significant DNA variations were identified in the 11 BHSD2 gene, however the frequency of $\mathrm{ENaC}$ variants previously shown to be associated with hypertension was significantly higher in study subjects (20\%) than in blood donors (3.7\%). The authors concluded that variants of the $\mathrm{ENaC}$ subunits may render some individuals sensitive to licorice-induced hypertension [11].

As the presented patient suffered from migraines, it is also interesting to mention a growing evidence linking RAAS with migraines and the role of RAAS blockage in treatment of migraines [12].

Although the patient did not give any history to drug allergy, a subclinical hypersensitivity to licorice could not be excluded. Literature reports several cases of licorice induced allergic reactions, such as rashes or occupational asthma $(13,14]$. Even though the literature does not report any case of licorice induced allergic coronary spasm, such possibility exists. Allergic coronary spasm progressing to myocardial injury constitutes Kounis syndrome [15]. This syndrome is not a rare disease but is a rarely diagnosed condition. One could consider licorice patch test to further evaluation.

\section{Conclusion}

Hypokalemia in a hypertensive patient should alert a clinician to inquire about licorice ingestion. Licorice candies are a widely available low fat snack and patients might be unaware of its side effects. Excessive licorice intake is also possible from tobacco chewing. Primary care providers, specialists and nutritionists who care for cardiac patients play an important role in indentifying potentially deleterious eating habits. Promotion of "heart healthy snacks", for example moderate consumption of dark chocolate and nuts, might lead to improvement in vascular health.

We anticipate increasing evidence of the role of 11 BHSD2 and steroids for both normal and pathologic cardiovascular function. It is likely that work in this area will lead to new indications for MR antagonists in the treatment of cardiovascular disease.

\section{References}

1. David Gardner, Dolores Shoback (2011) Greenspan's Basic \& Clinical Endocrinology, Chapter 11. Endocrine hypertension. Access Medicine from McGraw-Hill Companies.

2. Walker BR (2007) Glucocorticoids and cardiovascular disease. Eur J Endocrinol 157: 545-559

3. Dobbins KR, Saul RF (2000) Transient visual loss after licorice ingestion. J Neuroophthalmol 20: 38-41.

4. Morgan RD, Chou SH, Stelfox HT (2011) Posterior reversible encephalopathy syndrome in a patient following binge licorice ingestion. J Neurol 1720-1722.

5. www.hersheys.com/nutrition/licorice.asp/

6. Stern S, Bayes de Luna A (2009) Coronary artery spasm: a 2009 update Circulation 119: 2531-2534

7. Asl MN, Hosseinzadeh H (2008) Review of pharmacological effects of Glycyrrhiza sp. and its bioactive compounds. Phytother Res 22: 709-724. 
Citation: Konik E, Kurtz EG, Sam F, Sawyer D (2012) Coronary Artery Spasm, Hypertension, Hypokalemia and Licorice. J Clin Case Rep 2:143. doi:10.4172/2165-7920.1000143

8. Ruschitzka F, Quaschning T, Noll G, deGottardi A, Rossier MF, et al. (2001) Endothelin 1 type A receptor antagonism prevents vascular dysfunction and hypertension induced by 11 beta-hydroxysteroid dehydrogenase inhibition: role of nitric oxide. Circulation 103: 3129-3135.

9. Quaschning T, Ruschitzka F, Niggli B, Lunt CM, Shaw S, et al. (2001) Influence of aldosterone vs. endothelin receptor antagonism on renovascular function in liquorice-induced hypertension. Nephrol Dial Transplant 16: 2146-2151.

10. Sobieszczyk P, Borlaug BA, Gornik HL, Knauft WD, Beckman JA (2010) Glycyrrhetinic acid attenuates vascular smooth muscle vasodilatory function in healthy humans. Clin Sci (Lond) 119: 437-442.

11. Miettinen HE, Piippo K, Hannila-Hanelberg T, Paukku K, Hiltunen TP, et al.
(2010) Licorice-induced hypertension and common variants of genes regulating renal sodium reabsorpiton. Ann Med 42: 465-474

12. Gales BJ, Bailey EK, Reed AN, Gales MA (2010) Angiotensin-converting enzyme inhibitors and angiotensin receptor blockers for the prevention of migraines. Ann Pharmacother 44: 360-366

13. Benomar S, Ismaili N, Koufane J, Senouci K, Hassam B (2010) Fixed food eruption caused by liquorice. Ann Dermatol Venereol 137: 121-123.

14. Cartier A, Malo JL, Labrecque M (2002) Occupational asthma due to liquorice roots $57: 863$

15. Kounis NG, Mazarakis A, Tsigkas G, Giannopoulos S, Goudevenos J (2011) Kounis syndrome: a new twist on an old disease; Future Cardiol 7: 805-824 